\title{
Influência de Espaçadores na Corrosão de Armaduras em Concretos Induzidos por Carbonatação
}

\author{
P. H. R. J. Marques ${ }^{1}$, R. B. V. Andrada ${ }^{1}$, E. C. B. Monteiro ${ }^{1,2}$, W. W. Silva ${ }^{2 *}$ \\ *Autor de Contato: wildsonws@gmail.com \\ ${ }^{1}$ Departamento de Engenharia Civil, Universidade Católica de Pernambuco, Recife, Brasil \\ ${ }^{2}$ Departamento de Engenharia Civil, Universidade de Pernambuco, Recife, Brasil
}

\begin{abstract}
RESUMO
A vulnerabilidade das estruturas de concreto armado pode estar associada a alguns pontos de fragilidade. Objetivou-se avaliar o efeito de espaçadores na corrosão da armadura desencadeada por carbonatação. Corpos de prova de concreto armado foram submetidos à ensaios de indução da penetração de $\mathrm{CO}_{2}$, velocidade de onda ultrassônica, profundidade de carbonatação e perda gravimétrica da massa das armaduras. Identificou-se que os corpos de prova com espaçadores de argamassa industrializada foram os que mais apresentaram indícios de corrosão. Esse estudo limitou-se ao cobrimento da armadura de $2,5 \mathrm{~cm}$, entretanto, realizadas de forma ampla e diversificada. Os espaçadores influenciaram a entrada de $\mathrm{CO}_{2}$, favorecendo a despassivação e perda da massa gravimétrica das barras de aço.
\end{abstract}

Palavra-Chave: Corrosão; Concreto; Carbonatação; Espaçadores; Durabilidade.

\begin{abstract}
The vulnerability of reinforced concrete structures may be associated with some points of weakness. The objective was to evaluate the effect of spacers on the corrosion of the reinforcement triggered by carbonation. Reinforced concrete specimens were subjected to tests to induce $\mathrm{CO} 2$
\end{abstract}


penetration, ultrasonic wave speed, carbonation depth and gravimetric loss of the reinforcement mass. It was identified that the specimens with industrialized mortar spacers were the ones that most showed signs of corrosion. This study was limited to covering the $2.5 \mathrm{~cm}$ reinforcement, however, carried out in a wide and diversified manner. The spacers influenced the entry of $\mathrm{CO} 2$, favoring the depassivation and loss of the gravimetric mass of the steel bars.

Keywords: Corrosion; Concrete; Carbonation; Spacers; Durability.

\section{RESUMEN}

La vulnerabilidad de las estructuras de hormigón armado puede estar asociada con algunos puntos débiles. El objetivo fue evaluar el efecto de los espaciadores sobre la corrosión del refuerzo provocada por la carbonatación. Las probetas de hormigón armado se sometieron a ensayos para inducir la penetración de $\mathrm{CO} 2$, la velocidad de la onda ultrasónica, la profundidad de carbonatación y la pérdida gravimétrica de la masa de la armadura. Se identificó que las probetas con espaciadores de mortero industrializado eran las que más presentaban signos de corrosión. Este estudio se limitó a cubrir la armadura de $2,5 \mathrm{~cm}$, sin embargo, se llevó a cabo de forma amplia y diversificada. Los espaciadores influyeron en la entrada de CO2, favoreciendo la despasivación y pérdida de la masa gravimétrica de las barras de acero.

Palabras clave: Corrosión; Hormigón; Carbonatación; Espaciadores; Durabilidad.

\section{INTRODUÇÃO}

A deterioração das estruturas de concreto armado devido a corrosão da armadura é sem dúvida um dos principais problemas que comprometem a durabilidade das estruturas, implicando em sérios efeitos negativos de ordem estrutural, tais como: fissuração do concreto e perda de seção das barras de aço, prejuízos da aderência armadura/concreto, flechas e deformações excessivas da estrutura, destacamento do concreto e em estágios mais avançados, riscos de colapso parcial ou total da estrutura.

Os custos com manutenção das estruturas de concreto armado, principalmente causadas pelo envelhecimento, ainda são bem elevados. Os serviços de reparo e proteção de estruturas de concreto armado vem crescendo, exigindo a criação de novas soluções, para minimização dos problemas e diminuição nos custos de reparo (Ribeiro, 2014).

A presente pesquisa buscou avaliar o desempenho do espaçador quanto à corrosão do aço em peças de concreto armado, submetidos a carbonatação acelerada, sugerindo que estes elementos podem ser um ponto de fragilidade para a entrada de agentes agressivos como os íons cloretos e gás carbônico (Adamatti, 2016). Apesar da carbonatação ser um tema bastante discutido, o grande número de pesquisas, relacionadas aos espaçadores, ocorrem mais no âmbito dos íons cloretos. Foi utilizado o método de aceleração da carbonatação por meio de câmara de carbonatação, em corpos de prova prismáticos de concreto com barras de aço, contendo ou não espaçadores de argamassa em seu interior. Utilizou-se o método de ultrassom, avaliando a homogeneidade do concreto dos corpos de prova prismáticos na presença e ausência dos espaçadores. Foi utilizado o método de potencial de corrosão, a fim de aferir e avaliar o grau da corrosão das armaduras, nos corpos de prova prismáticos. 
Foram realizados ensaios e análises complementares em cada espaçador de argamassa, são eles: análise da variação dimensional, ensaio de resistência à compressão, ensaio de absorção por capilaridade e ensaio de absorção por imersão, logo após foram realizados ensaios complementares no concreto utilizado para confecção dos corpos de prova prismáticos, são eles: ensaio de resistência à compressão, ensaio de absorção por capilaridade e ensaio de absorção por imersão. Por fim, foram realizados o ensaio de profundidade de carbonatação, nos corpos de prova prismáticos, e uma análise da perda de massa gravimétrica das barras de aço.

Com relação as variáveis envolvidas na pesquisa, houve a variável independente, no caso o tipo de espaçador. No caso, os espaçadores escolhidos seguiram o critério de maior utilização na construção civil da Região Metropolitana do Recife (RMR), em Pernambuco, sendo eles compostos de argamassa, com a diferença entre a produção: um tipo industrializado e o outro confeccionado no próprio canteiro de obra. Como variável dependente, no aço: corrosão do aço CA-50 e Ø 6,3mm. São as variáveis de resposta do experimento: potencial de corrosão e perda de massa gravimétrica no concreto: resistência à compressão axial, absorção capilar e absorção por imersão, porosidade, profundidade de carbonatação acelerada. No espaçador: resistência à compressão axial, absorção capilar e absorção por imersão, profundidade de carbonatação acelerada. Considerou-se como condições fixas do experimento a idade dos ensaios e o modo de indução do ataque corrosivo.

\section{PROCEDIMENTO EXPERIMENTAL}

\subsection{Materiais Utilizados}

O cimento utilizado para a produção do concreto foi do tipo CPII Z - 32, de acordo com a NBR 16697:2018, escolhido por ser um dos mais utilizados na construção civil da RMR, sempre oriundo do mesmo lote de fabricação.

Como agregado miúdo, foi utilizada areia média, fornecida na região de Recife/PE e proveniente do leito do rio. A massa específica de acordo com a metodologia NBR NM 52 (ABNT, 2009), possui um valor de $2,62 \mathrm{~g} / \mathrm{cm}^{3}$ e a dimensão máxima característica, de acordo com a metodologia da NBR NM 248 (ABNT, 2003), possui um valor de 2,40mm. Como agregado graúdo, foi utilizada pedra britada de rocha diabásica. As pedras apresentam dimensão máxima de 12,5 mm, compatível com os corpos de provas prismáticos com tamanho reduzido. Após realizada a composição granulométrica, foi possível classificar, segundo a norma brasileira NBR 7211:2009, como brita 0 . Foi utilizada água potável para mistura dos concretos, proveniente da rede de abastecimento da Universidade Católica de Pernambuco (UNICAP).

Os corpos de prova de aço empregados na pesquisa foram obtidos através de barras de diâmetro nominal 6,3 $\mathrm{mm}$, categoria CA-50 e comprimento de $10 \mathrm{~cm}$.

\subsection{Os Espaçadores}

Os espaçadores utilizados para a confecção dos corpos de prova foram de dois tipos:

- Espaçador de argamassa industrializados (EPI): produzidos e adquiridos em fábrica na região de Recife/PE, seguindo procedimentos e normas do próprio fabricante. Resistência à compressão de $25 \mathrm{Mpa}$ e cobrimento nominal de 2,5 cm, segundo o fabricante.

- Espaçador de argamassa produzidos em obra (EPO): confeccionados in loco e cedidos por uma obra na região de Recife/PE, sem controle de qualidade, cobrimento nominal de 2,5 $\mathrm{cm}$ e seguindo procedimentos próprios. O traço utilizado pela obra foi de um volume de cimento para cinco volumes de areia, medidos em latas ou baldes. Não existe uma relação a/c (água/cimento) certa, a água é colocada até que o responsável pela execução considere que a compacidade da mistura está adequada para moldagem, isto sem nenhum procedimento ou controle formalizado. Este mesmo método é utilizado em várias obras da região. 
Os espaçadores foram submetidos a ensaios de resistência à compressão, análise dimensional, absorção de água por capilaridade, absorção de água por imersão seguindo parâmetros e procedimentos das normas de concreto NBR 5739:2007, NBR 9778:2005 e NBR 9779:2012, a fim de caracterizar os espaçadores utilizados.

\subsection{Dosagem dos corpos de prova}

Os corpos de prova utilizados na pesquisa, tanto para os ensaios complementares quanto para os ensaios de corrosão, foram definidos em função do planejamento experimental e levando em consideração a disponibilidade de espaço físico na câmera de ensaio. Foram utilizados corpos de prova cilíndricos com dimensões $10 \mathrm{~cm}$ x $20 \mathrm{~cm}$ para os ensaios de resistência à compressão axial, absorção por imersão, absorção capilar, em concreto simples.

Para os ensaios voltados à corrosão das armaduras, os corpos de prova com aço tiveram forma prismática com dimensões $10 \mathrm{~cm}$ x $10 \mathrm{~cm}$ x $6 \mathrm{~cm}$, conforme mostrado nas Figuras 1, 2 e 3 . Em outras pesquisas relacionadas com o tema da corrosão do aço (Castro, 2003; Monteiro, 2002; Vieira, 2003; Vaghetti 2005), também foram confeccionados corpos de prova similares, com pequenas alterações de tamanho e disposições da armadura.

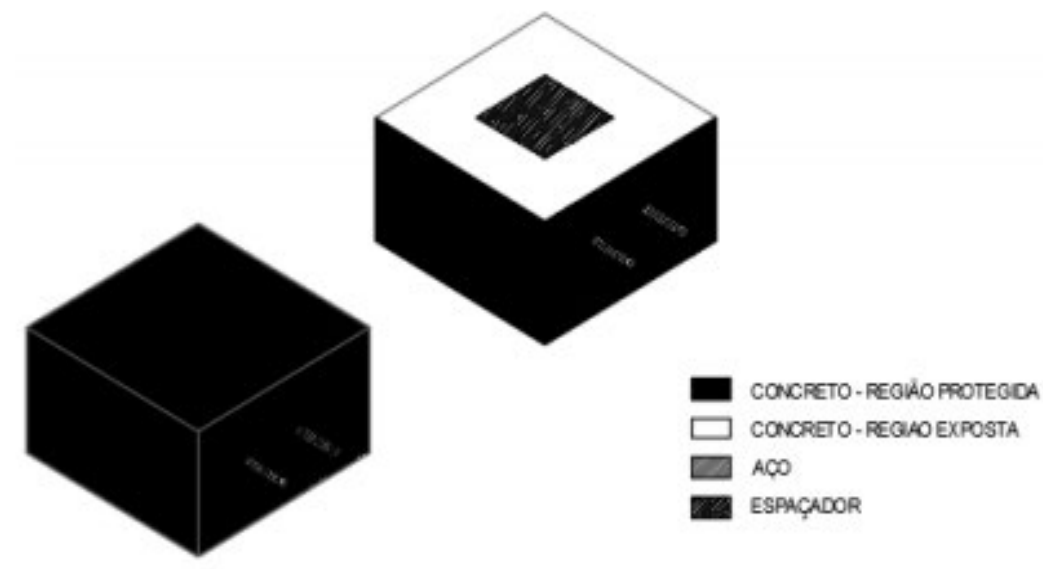

Figura 1. Perspectiva do corpo de prova.
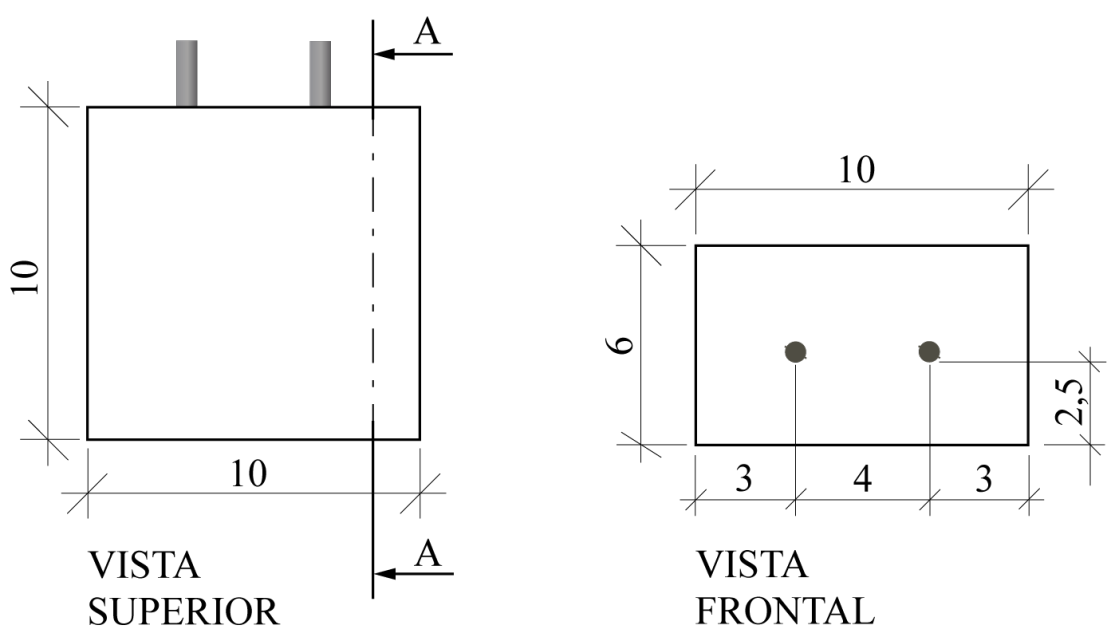

Figura 2. Vistas superior e frontal. 


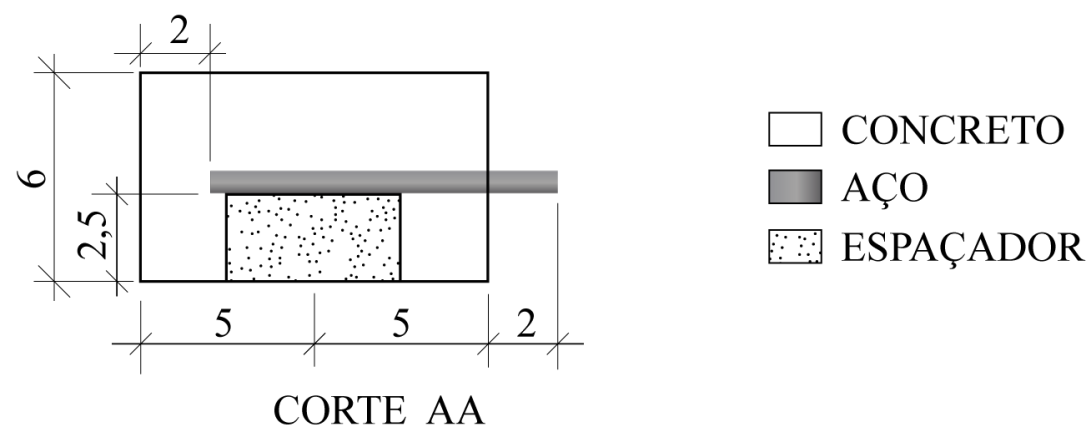

Figura 3. Corte AA da vista superior.

As dimensões dos corpos de prova com aço, adotadas para esse experimento, satisfazem as exigências da NBR6118:2014 com relação à dimensão máxima característica do agregado graúdo. Para cada tipo de espaçador foram feitos corpos de prova com espaçadores de argamassa produzidos em obra - CPAO com 20 unidades e corpos de prova com espaçadores de argamassa industrializados - CPAI com 20 unidades. Também foram moldados corpos de prova sem espaçador para referência (CPREF) com 20 unidades. As armaduras foram inseridas com auxílio de suporte, atendendo o cobrimento constante de $2,5 \mathrm{~cm}$.

\subsection{Dosagem do concreto}

Com a finalidade de resultados mais próximo da realidade, foi definido para o experimento um único traço usual nas obras da região de Recife/PE, adotando-se todos os parâmetros como constante para os corpos de prova e resistência à compressão estimada de $\leq 30 \mathrm{MPa}$. O traço estabelecido para cimento: areia: brita e relação água/cimento foram: 1:0,75:2,75:0,55.

\subsection{Moldagem e cura}

A moldagem dos corpos de prova foi planejada para se ter o maior grau possível de homogeneidade e principalmente precisão de forma, dimensões e posicionamento de barra conforme Figuras 4, 5, 6 e 7. A forma foi feita por um conjunto composto por madeira e aço, de forma a manter a rigidez do sistema durante todo ensaio, sem alterar nenhuma dimensão dos corpos de prova devido a deformação da madeira.

Foi utilizada uma betoneira no procedimento de mistura do concreto. Posteriormente o concreto foi lançado por uma das faces paralelas à barra de aço em duas camadas, sendo cada camada adensada mecanicamente durante 10 segundos. Os corpos de prova foram desmoldados após $24 \mathrm{~h}$ e mantidos em câmara úmida por 28 dias.

Após a cura e o ensaio de ultrassom, 5 faces do corpo de prova foram protegidas por uma tinta (Emulsão asfáltica) à base de água para concreto impermeabilizante, visando garantir que a penetração do dióxido de carbono se dê apenas pela face que contém o espaçador. Transcorridos os 28 dias de cura e após a pintura, os corpos de prova iniciaram um procedimento de secagem em ambiente de laboratório por 30 dias. 

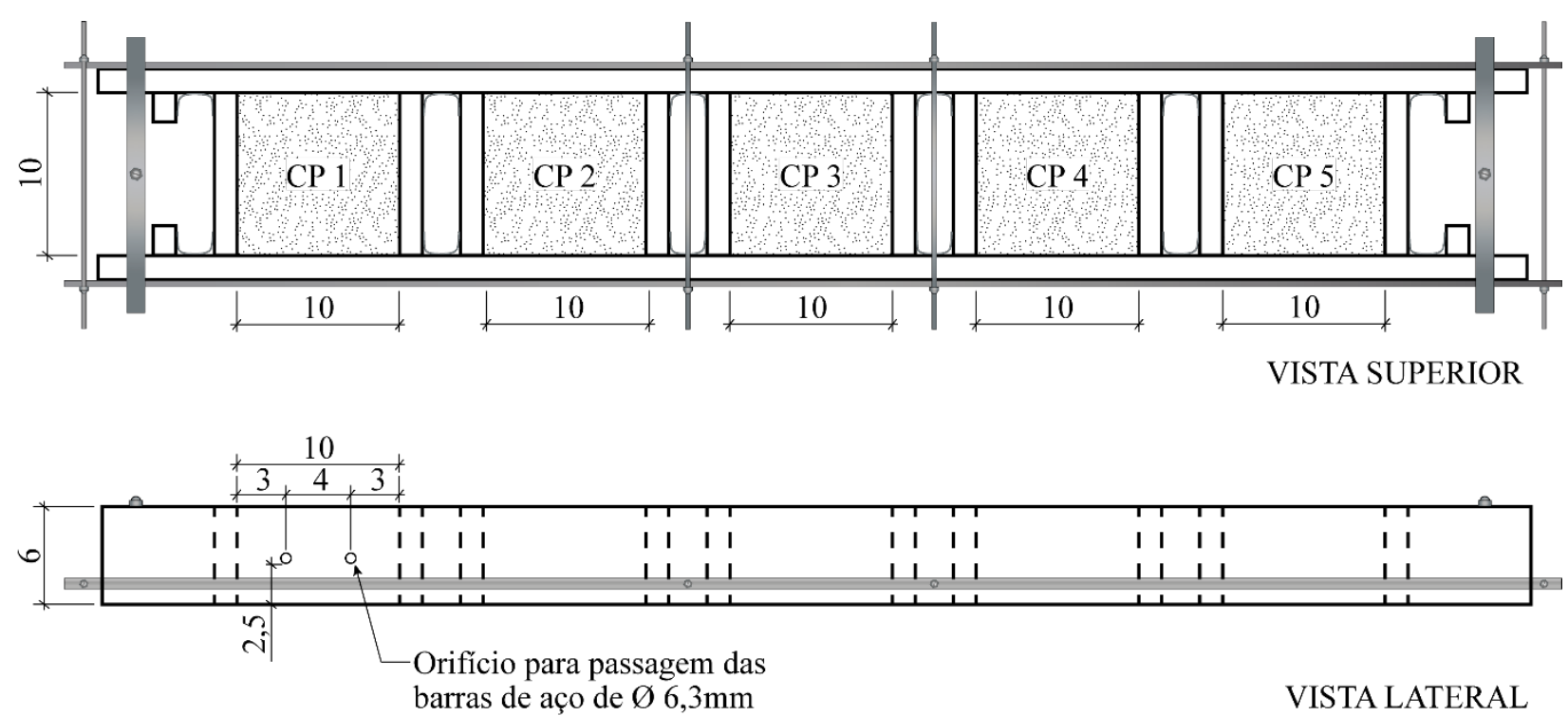

Figura 4. Esquema de moldagem dos corpos de prova.

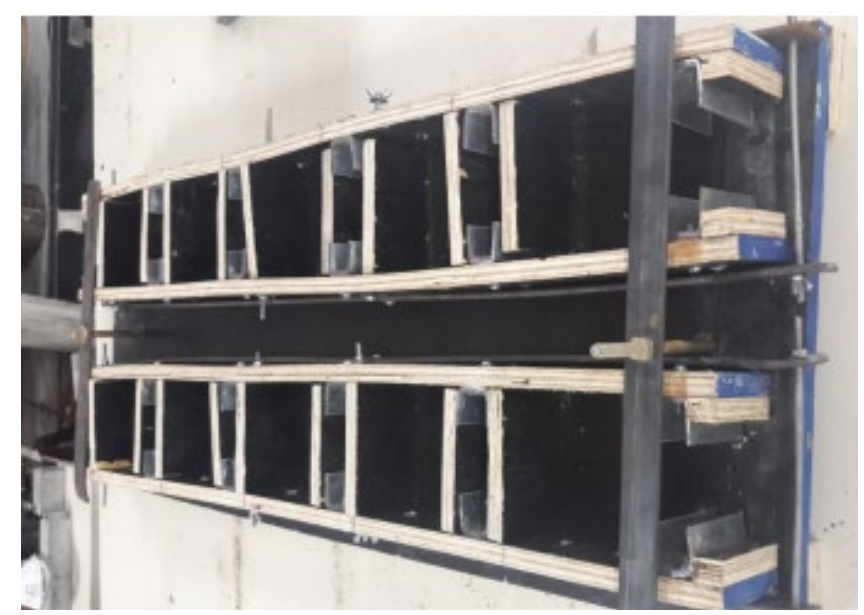

Figura 5. Forma utilizada para moldagem dos corpos de prova.

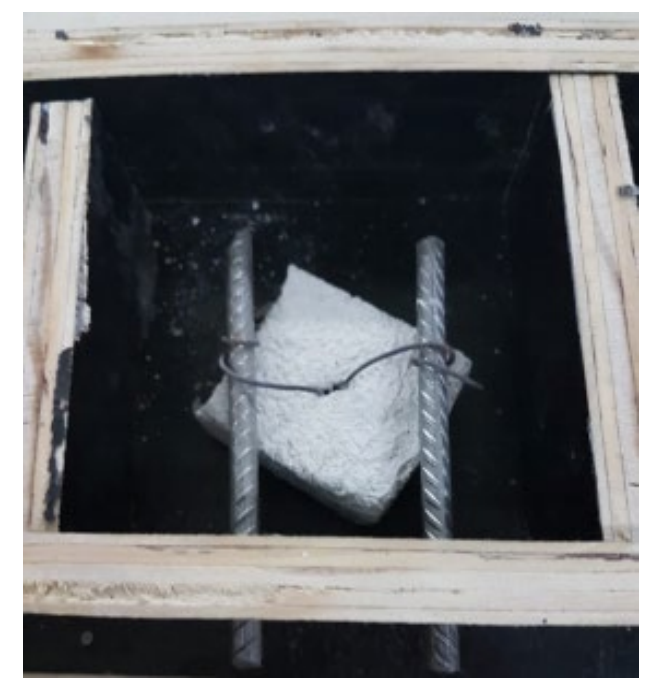

Figura 6. Preparação da fôrma com espaçador industrializado de argamassa. 


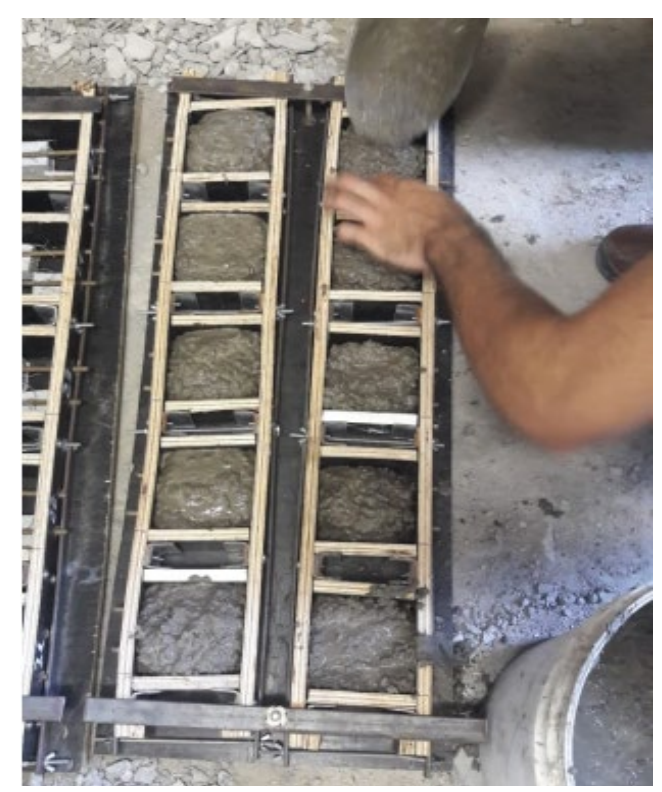

Figura 7. Preparação da fôrma com espaçador industrializado de argamassa.

\subsection{Determinação da velocidade de propagação da onda ultrassônica}

O ensaio tem como objetivo determinar a propagação de ondas dos 60 corpos de prova ensaiados (20 de referência, 20 com espaçadores industrializados de argamassa e 20 com espaçadores de argamassa produzido em obra), a fim de detectar as variações no concreto ao longo do tempo, devido aos espaçadores. O ensaio foi executado de acordo com a NBR 8802:2013. Para que garantisse que as superfícies estivessem secas, foram retirados da cura 1 hora antes de serem ensaiados e antes dos corpos de prova passarem pela pintura impermeabilizante. A realização do ensaio de propagação das ondas ultrassônicas ocorreu por meio do equipamento PUNDIT (Portable Ultrassonic Non-Destructive Digital Indicating Tester) da C.N.S Electronics, Ltd, com transdutores de frequência de $54 \mathrm{kHz}$ e cabos de $3 \mathrm{~m}$ de comprimento.

As leituras foram realizadas nos corpos de prova prismáticos, para permitir o acoplamento entre as faces dos transdutores e o concreto foi aplicada uma fina camada de gel. Logo após, os transdutores foram posicionados em faces opostas dos corpos de prova. Para cada ensaio registou-se o tempo de percurso das ondas (em $\mu \mathrm{s})$ e mediu-se o comprimento do corpo de prova.

\subsection{Método de indução e aceleração da corrosão}

O método empregado para provocar a despassivação da armadura foi a carbonatação acelerada, utilizado por diversos pesquisadores, tais como: (Cadore, 2008; Nascimento, 2017; Papadakis, 2000; Vaghetti, 2005; Vieira, 2003). Para isso o ensaio foi realizado em câmera de carbonatação construída. O procedimento consiste em utilizar uma câmara na qual introduz-se $\mathrm{CO} 2 \mathrm{em}$ teores superiores aos encontrados na atmosfera.

A câmara de carbonatação utilizada na pesquisa foi desenvolvida seguindo os princípios de (Bauer, 1995) com algumas alterações. O gás na concentração de 100\%, é injetada na câmara em sua parte inferior, sua saída é localizada na parte superior da câmara, como o ar é mais denso que o CO2, este se desloca por entre os corpos de prova expulsando o ar pela saída.

A câmara foi montada em uma caixa plástica de 80 litros, tamanho ideal para a introdução em seu interior de 20 corpos de prova com menor consumo de CO2, a saída e entrada de ar possuem registro para controle do fluxo. A vedação da câmara foi feita com silicone. O sistema utilizado para regular a pressão e a vazão do $\mathrm{CO} 2$ é composto por um cilindro de $\mathrm{CO} 2$ de $10 \mathrm{~kg}$ acoplado em um regulador de vazão e pressão, podendo-se assim regular a vazão de gás que entra na câmara e a pressão no cilindro. Após o regulador de pressão foi colocada uma mangueira de silicone para 
injeção de $\mathrm{CO} 2$ na câmara. Esta também é dotada de um sistema de controle, para monitoramento das variáveis (concentração de $\mathrm{CO} 2$, temperatura e umidade) no interior durante o ensaio, vide Figuras 8, 9 e 10.

O sistema é composto por:

Módulo sensor MQ-135: é um sensor de alta sensibilidade para gases tóxicos (NH3, NOx, C6H6, $\mathrm{C} 2 \mathrm{H} 6 \mathrm{O}$ e $\mathrm{CO} 2$ ), garante uma resposta rápida ao sistema de monitoramento do ar. O modulo sensor é conectado ao Arduino ligando-se o pino positivo no 5V, o pino negativo no GND e o pino AOUT em uma porta analógica, dessa forma foi possível realizar a leitura do sinal analógico e acompanhar através do Serial Monitor do Arduino.

Módulo sensor de umidade e temperatura DHT-11: é um sensor que faz leitura de umidade e temperatura e informa ao microcontrolador como um Arduino. Possui saída digital garantindo alta confiabilidade e estabilidade.

Arduino Uno R3: Utiliza uma linguagem de programação $\mathrm{C} / \mathrm{C}++$ para o monitoramento da câmara. O microcontrolador lê os valores enviados pelos sensores e analisa conforme código de programação. O código foi elaborado e enviado ao microcontrolador através do software IDE arduino 1.8.5, possibilitando a leitura dos sinais enviados pelos sensores a cada segundo, permitindo assim o monitoramento da câmara em tempo real.

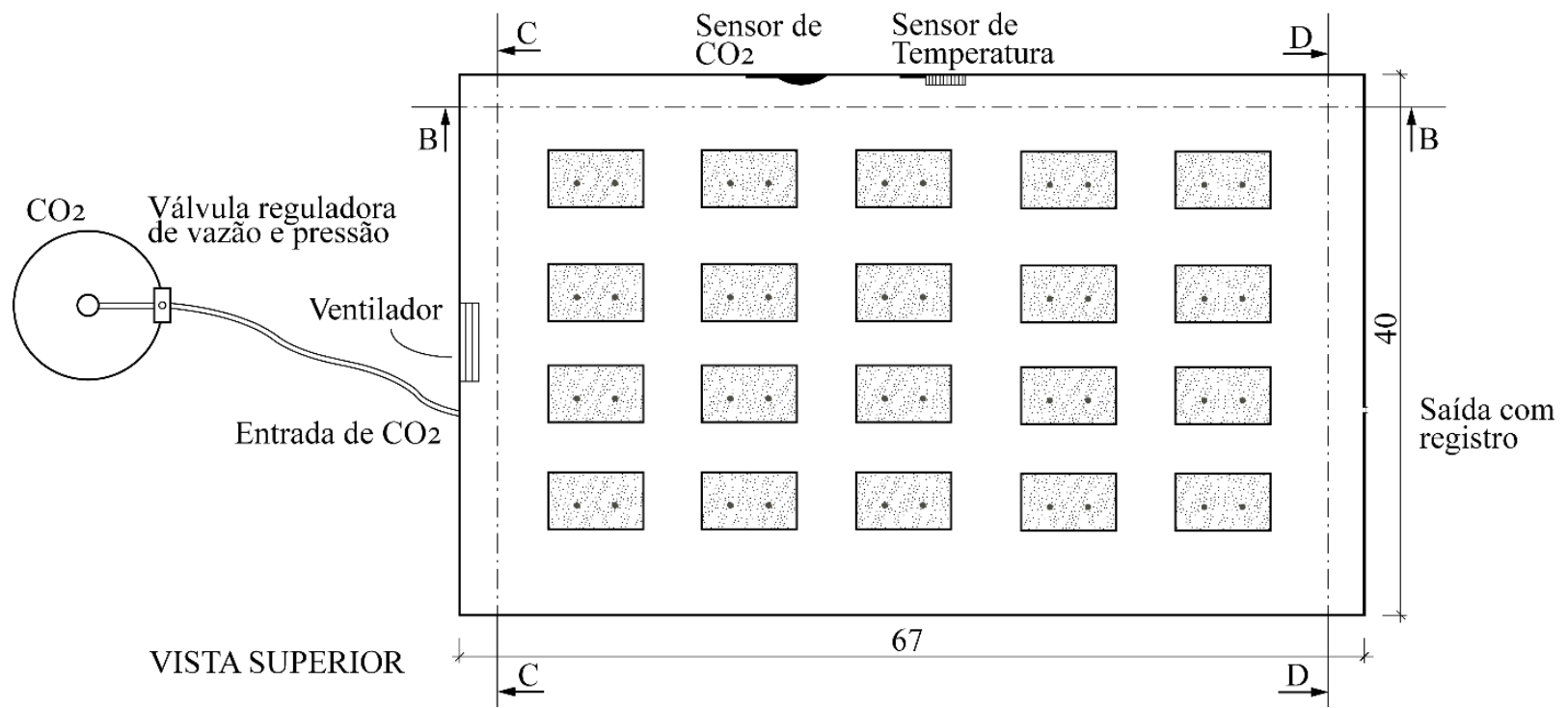

Figura 8. Esquema de câmara de carbonatação montada.

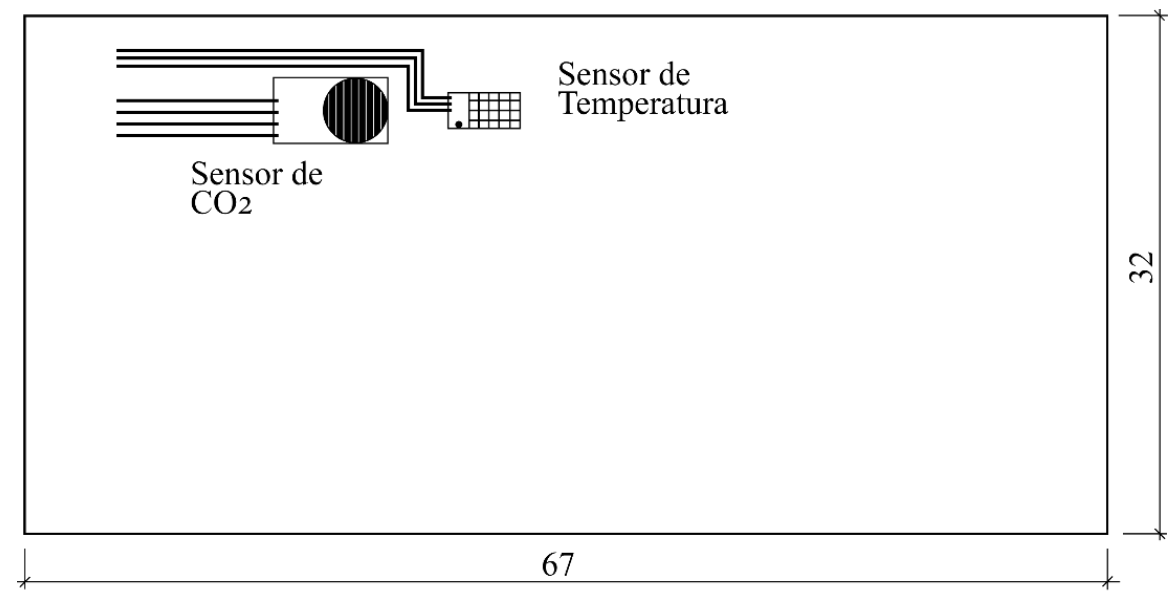

CORTE BB

Figura 9. Detalhes da câmara de carbonatação montada, corte BB. 

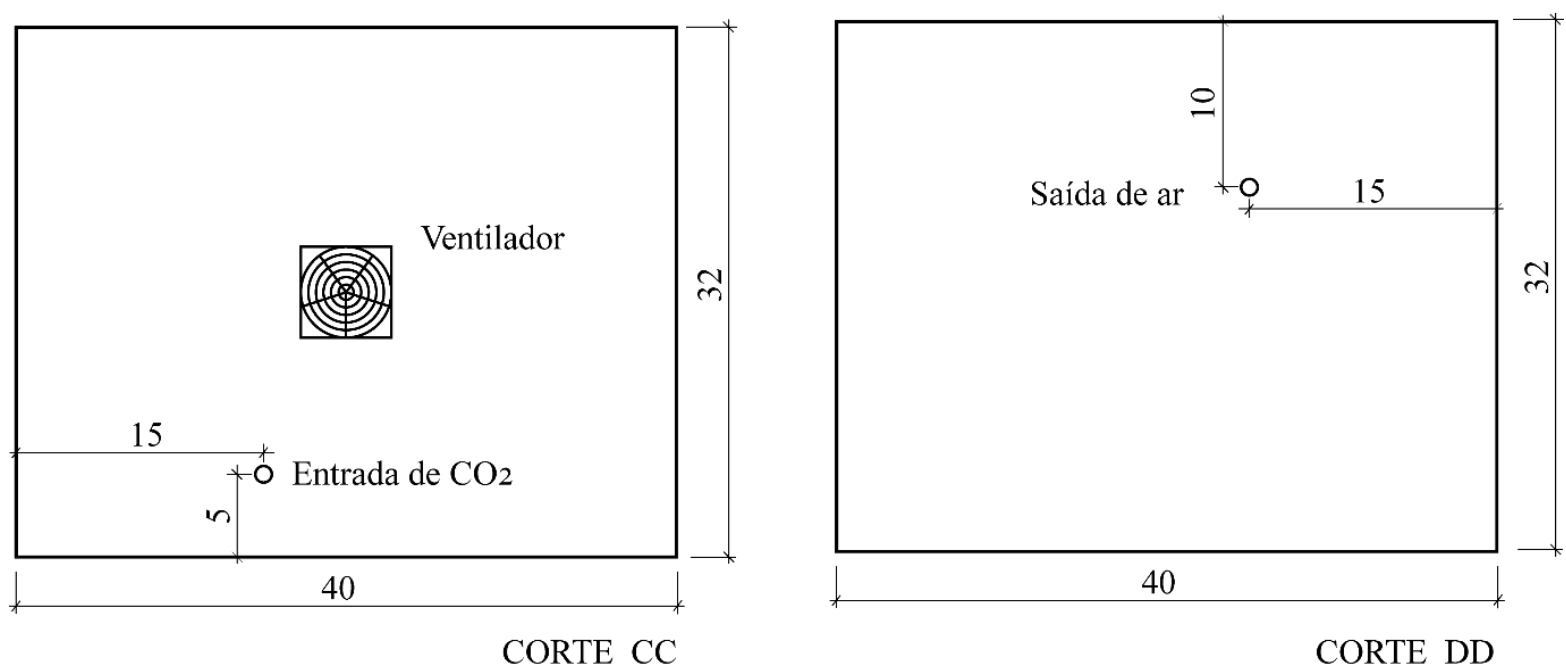

Figura 10. Detalhes da câmara de carbonatação montada, corte CC e DD.

\section{ENSAIOS}

Os métodos e ensaios realizados, foram determinados e encontram-se de acordo com o fluxograma na Figura 11, esclarecendo os processos a serem realizados.

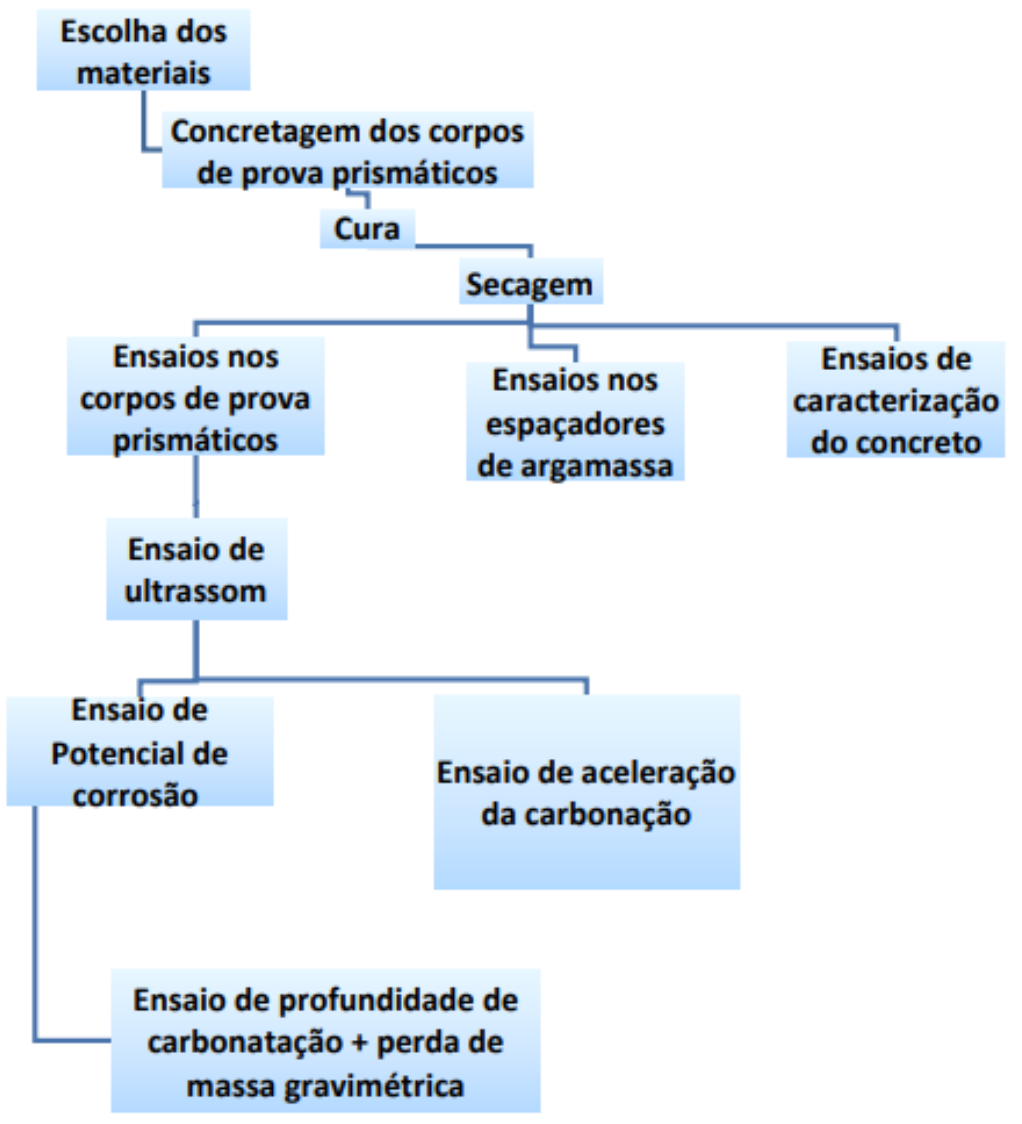

Figura 11. Fluxograma com metodologia de ensaios a serem realizados.

O ensaio acelerado de corrosão por carbonatação constituiu em submeter os corpos de prova à ação de $\mathrm{CO} 2$, em câmara de carbonatação acelerada com concentração de $\mathrm{CO} 2 \approx 100 \%$. Os corpos de 
prova, ao saírem da cura úmida, encontravam-se saturados, e por isto, não possuíam condições de serem submetidos imediatamente à carbonatação devido aos poros se encontrarem cheios de água, dificultando o ingresso de CO2. Sendo assim, fez-se necessário um período de secagem em sala climatizada por 30 dias com temperatura igual a $(25 \pm 2)^{\circ} \mathrm{C}$ e umidade relativa igual a $(70 \pm 2) \%$ antes de começar o ensaio de carbonatação.

Aos 58 dias, após período de cura úmida e secagem em sala climatizada, foram realizadas nos corpos de prova as primeiras medidas eletroquímicas (medidas de referência), que determina o potencial de corrosão. A partir de então os corpos de prova foram colocados na câmara de carbonatação acelerada para início do ensaio.

O ensaio foi realizado através da aplicação diária de dois fluxos intermitentes de CO2 na câmara de carbonatação, com vazão de 201/min e duração de 4 minutos. Como o volume total da câmara era de 80 1, a cada fluxo aplicado injetava-se um volume de CO2 correspondente a aproximadamente $100 \%$ do volume total da câmara.

As medidas eletroquímicas, para determinação do potencial de corrosão, foram realizadas após 24 horas, 48 horas, 72 horas e 96 horas de permanência dos corpos de prova na câmara de carbonatação, sendo posteriormente realizadas a cada semana. $\mathrm{O}$ ensaio acelerado de corrosão por carbonatação foi realizado por um período total de 30 dias.

\subsection{Potencial de corrosão}

O estado superficial do aço foi avaliado mediante as leituras eletroquímicas do potencial de corrosão, segundo método descrito na ASTM C 876 (2015). A medida do potencial de corrosão de meia célula tem como base medir a velocidade e evolução do processo corrosivo da armadura, obtendo o potencial de corrosão através de um eletrodo de referência, o qual indica aproximadamente a probabilidade de ocorrência da corrosão e a consequente classificação do estado do concreto. (Lima, 2016).

O equipamento utilizado foi CANIN+, da marca Proceq, uma meia célula composta por cobre/sulfato $(\mathrm{Cu} / \mathrm{CuSO} 4)$, utilizando uma vareta de cobre imersa em solução saturada com cobre, mantendo um potencial constante de $10 \mathrm{M} \Omega$. O eletrodo de referência é conectado por meio de um voltímetro de alta impedância ao reforço do aço, devendo ser deslocado na superfície do concreto em forma de grade, definida de acordo com a geometria da estrutura analisada, acima da superfície de concreto. As leituras de potencial foram realizadas após os 58 dias de cura (28 dias na cura úmida +30 dias de secagem), sempre semanalmente, avaliando o estado qualitativo do aço ao longo do tempo.

\subsection{Profundidade de carbonatação}

A determinação da profundidade de carbonatação em ensaio acelerado foi realizada nos corpos de prova prismáticos $(10 \mathrm{~cm} \times 10 \mathrm{~cm} \times 6 \mathrm{~cm}) \mathrm{com}$ aço, curados por 1 dia nos moldes, 28 dias na cura úmida e 30 dias de pré-condicionamento. Ao completarem 59 dias, os corpos de prova foram depositados na câmara de carbonatação acelerada. A espessura de carbonatação foi determinada após 30 dias de permanência na câmara, sendo nessa idade rompidos (fraturados pela metade) na prensa por compressão. Após o rompimento, foram limpas as superfícies de cada metade dos corpos de prova, para a retirada das partículas soltas decorrentes da fratura e receberam aspersão de solução de fenolftaleína a 1\% segundo método RILEM CPC18/1988. Depois de decorrido aproximadamente 30 minutos, foi feita a leitura da profundidade carbonatada de cada face com auxílio de paquímetro. A espessura carbonatada $(\mathrm{mm})$ foi tomada sendo a média aritmética das leituras dos 4 lados. 


\subsection{Perda de massa gravimétrica e taxa de corrosão gravimétrica}

A perda de massa de cada barra seguiu recomendação do método ASTM G1 (1990). As barras foram limpas utilizando o mesmo método descrito no subitem 3.3.3 que fora inicialmente realizado quando as mesmas estavam sujas com o co-produto oriundo da oxidação da superfície do aço. Após a limpeza das barras de aço, elas foram pesadas com a mesma balança utilizada na determinação da massa inicial, obtendo-se as massas finais após a corrosão. A perda de massa (mg), foi calculada pela diferença entre a massa inicial e a massa final de cada barra.

\section{ENSAIOS}

\subsection{Resistência à compressão do concreto}

Foram moldados corpos de prova cilíndricos $(10 \mathrm{~cm}$ x $20 \mathrm{~cm})$ simultaneamente aos prismáticos e posteriormente ensaiados aos 7 e 28 dias de acordo com os procedimentos da NBR 5738:2015 e NBR 5739:2018. Os resultados encontram-se na Tabela 1:

Tabela 1. Resultados do ensaio de resistência à compressão do concreto

\begin{tabular}{|c|c|c|c|c|c|c|}
\hline \multicolumn{7}{|c|}{ Ensaio de Resistência à Compressão } \\
\hline Idade & Traço & CP's & $\begin{array}{c}\text { Carga } \\
\text { (tf) }\end{array}$ & $\begin{array}{l}\text { Tensão } \\
\text { (Mpa) }\end{array}$ & $\begin{array}{l}\text { Média } \\
(\mathrm{Mpa})\end{array}$ & $\begin{array}{c}\text { Média } \\
\text { Total } \\
(\mathrm{Mpa})\end{array}$ \\
\hline \multirow{6}{*}{7 dias } & \multirow{2}{*}{$\begin{array}{l}\text { CP. } \\
\text { REF. }\end{array}$} & 1 & 20,1 & 24,2 & \multirow{2}{*}{24,8} & \multirow{6}{*}{23,7} \\
\hline & & 2 & 20,7 & 25,4 & & \\
\hline & \multirow{2}{*}{ CP. AO } & 1 & 18,9 & 22,8 & \multirow{2}{*}{23,1} & \\
\hline & & 2 & 19 & 23,4 & & \\
\hline & \multirow{2}{*}{ CP. AI } & 1 & 19,2 & 23,6 & \multirow{2}{*}{23,2} & \\
\hline & & 2 & 18,5 & 22,7 & & \\
\hline \multirow{6}{*}{28 dias } & \multirow{2}{*}{$\begin{array}{l}\text { CP. } \\
\text { REF. }\end{array}$} & 3 & 25,4 & 31,2 & \multirow{2}{*}{31,1} & \multirow{6}{*}{31,2} \\
\hline & & 4 & 24,4 & 31 & & \\
\hline & \multirow{2}{*}{ CP. AO } & 3 & 27 & 32,6 & \multirow{2}{*}{32,4} & \\
\hline & & 4 & 26,7 & 32,1 & & \\
\hline & \multirow{2}{*}{ CP. AI } & 3 & 24,1 & 29 & \multirow{2}{*}{30} & \\
\hline & & 4 & 25,8 & 31 & & \\
\hline
\end{tabular}

\subsubsection{Resistência à compressão do concreto}

Também realizados em corpos de prova cilíndricos moldados simultaneamente aos prismáticos, seguindo parâmetros das normas NBR 9778:2005. Os resultados obtidos podem ser observados na Tabela 2: 
Tabela 2. Resultados dos ensaios de absorção de água, índice de vazios e massa específica do concreto

\begin{tabular}{lc}
\hline \multicolumn{2}{l}{ Ensaio de Absorção de água, índice de vazios e Massa específica } \\
\hline Característica & Resultado \\
\hline Absorção (\%) & 3,77 \\
\hline Índice de vazios (\%) & 8,52 \\
\hline Massa específica seca $(\mathrm{g} / \mathrm{l})$ & 2,26 \\
\hline Massa específica saturada $(\mathrm{g} / \mathrm{l})$ & 2,35 \\
\hline Massa específica real $(\mathrm{g} / \mathrm{l})$ & 2,57 \\
\hline
\end{tabular}

\subsubsection{Absorção por capilaridade}

Por fim foi realizado o ensaio de absorção capilar para caracterização do concreto. $O$ ensaio seguiu os parâmetros da norma NBR 9779:2012 e os resultados apresentaram resultados coerentes.

\subsection{Determinação da velocidade de propagação de onda ultrassônica}

Com base nos ensaios e resultados obtidos com os corpos de prova de referência, dos espaçadores produzidos em obra e espaçadores produzidos industrialmente, foi possível analisar que todas as famílias de corpos de prova ficaram entre a condição boa e excelente em relação a velocidade de propagação ultrassônica. Como esperado, os melhores resultados foram obtidos dos corpos de prova de referência pois em seu interior não havia nenhuma descontinuidade (espaçadores). Os corpos de prova com resultados menos favoráveis foram os com espaçadores produzidos em obra, devido principalmente ao fato do qual os espaçadores possuem uma grande variação dimensional e em todos os casos, suas dimensões são maiores que os espaçadores de argamassa industrializados.

\subsection{Ensaios de corrosão desencadeadas por carbonatação}

Os resultados apresentados no gráfico mostram nitidamente que os corpos de prova com espaçadores apresentam valores mais negativos de potencial de corrosão na evolução do ensaio de carbonatação acelerada. O gráfico pode ser visualizado na Figura 12.

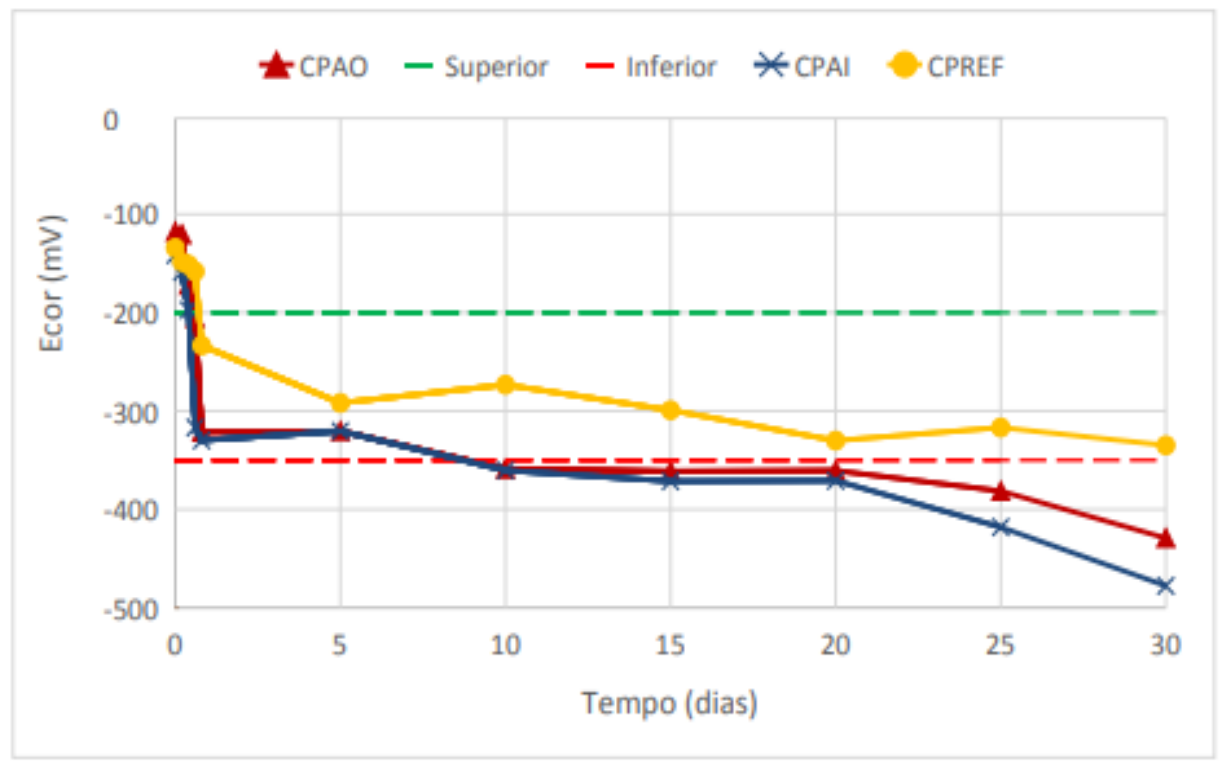

Figura 12. Evolução do potencial de corrosão - corpos de prova de referência, $\mathrm{CP}$ de argamassa industrializada, CP de argamassa produzida em obra. 


\subsection{Tempo de início da despassivação da armadura}

Considerando o tempo de início da despassivação do aço como sendo, qualitativamente, quando ocorre uma queda brusca (variações de mais de $100 \mathrm{mV}$, corrosão ativa segundo o ACI 222R/2001) nos potenciais de corrosão, pode-se definir aproximadamente o tempo em que ocorreu uma mudança significativa nos potenciais, caracterizando isso a provável despassivação do aço. $\mathrm{O}$ tempo de início da despassivação dos aços para as três famílias podem ser observados na tabela abaixo. Estão indicadas, também, as variações ocorridas nos potenciais $(\Delta \mathrm{E} \mathrm{em} \mathrm{mV})$ quando da provável despassivação dos aços.

Tabela 3. Tempo do início da despassivação

\begin{tabular}{|c|c|c|c|}
\cline { 2 - 4 } & CP REF & CP AI & CP AO \\
\hline Tempo de Início & - & 72 horas $\mathrm{E}=119,4 \mathrm{mV}$ & 96 horas $\mathrm{E}=115,6 \mathrm{mV}$ \\
\hline
\end{tabular}

\subsection{Perda de massa e taxa de corrosão gravimétrica}

A Tabela 4 apresenta os resultados das médias da perda de massa encontradas para as três famílias, pesadas logo após a limpeza.

Tabela 4. Perda de massa e taxa de corrosão gravimétrica

\begin{tabular}{|c|c|c|c|}
\hline \multirow{2}{*}{ Família } & \multicolumn{2}{|c|}{ Perda de massa } & \multirow{2}{*}{$\begin{array}{c}\text { Taxa de corrosão } \\
\text { (mm/ano) }\end{array}$} \\
\cline { 2 - 3 } & $\mathrm{mg}$ & $\%$ & 0,0125 \\
\hline CP REF & 67 & 0,54 & 0,0154 \\
\hline CP AI & 82 & 0,75 & 0,0146 \\
\hline CP AO & 79 & 0,67 & \\
\hline
\end{tabular}

\section{CONCLUSÕES}

Através dos ensaios realizados pode-se concluir que a análise de variação dimensional dos espaçadores, comprovou que os espaçadores de argamassa industrializados, em sua maioria, não atingiram o cobrimento solicitado de $2,5 \mathrm{~cm}$, ao contrário dos espaçadores de argamassa produzidos em obra, que ultrapassaram o cobrimento solicitado de $2,5 \mathrm{~cm}$ em todos os casos.

O ensaio de velocidade de propagação de onda ultrassônica, comprovou-se que a presença dos espaçadores gera uma descontinuidade considerável no interior do concreto.

A câmara de carbonatação mostrou eficiência satisfatória, tendo em vista que todas as armaduras das famílias com espaçadores CP AI e CP AO passaram da condição de passividade para a condição de corrosão das barras de aço.

Em relação ao tempo de início de despassivação da armadura, os corpos de prova com espaçadores apresentaram efeito significativo. A família CP AI apresentou o menor tempo de despassivação das armaduras, enquanto a família de referência CP REF não foi possível detectar mudança significativa nos potenciais a ponto de caracterizar uma possível despassivação do aço.

Em relação à variação do potencial de corrosão em função do tempo, o incremento de espaçadores no interior dos concretos foi significativo na variação do potencial de corrosão. Concretos com espaçadores atingiram valores mais negativos de potencial de corrosão ao longo do tempo, apresentando uma condição mais favorável à ocorrência de corrosão. 
Em relação à profundidade de carbonatação, o incremento de espaçadores no interior dos concretos, influenciaram significativamente uma maior profundidade de carbonatação. O aumento observado, em relação ao corpo de prova de referência, foi de $7,6 \%$ e $6,7 \%$ para os corpos de prova com espaçadores de argamassa industrializados e com espaçadores de argamassa produzidos em obra, respectivamente.

Em relação à perda de massa gravimétrica das barras, o incremento de espaçadores no interior dos concretos, acarretou uma maior perda de massa gravimétrica. Ao acrescentar os espaçadores de argamassa industrializados e espaçadores de argamassa produzidos em obra, obteve-se respectivamente, um aumento de $22,4 \%$ e $17,9 \%$ na perda de massa gravimétrica.

É possível afirmar, após todas as conclusões e procedimentos realizados, que os espaçadores influenciam diretamente não apenas na entrada de $\mathrm{CO} 2$ no concreto, diminuindo o tempo de início de despassivação das barras, como também na perda de massa gravimétrica das barras de aço e na profundidade de carbonatação. Os espaçadores de argamassa industrializados apresentaram um desempenho inferior em relação aos espaçadores produzidos em obra, quando avaliados do ponto de vista de carbonatação.

\section{REFERENCIAS}

Adamatti, D. S. (2016). "Análise da eficiência de espaçadores no concreto armado: impacto da corrosão por ions cloreto em diferentes condições de exposição”. Dissertação de Mestrado, Universidade Federal do Rio Grande do Sul, p. 35.

Associação Brasileira de Normas Técnicas. (1998). NM 67: Concreto - Determinação da consistência pelo abatimento do tronco de cone. Rio de Janeiro.

Associação Brasileira de Normas Técnicas. (2004). NBR 14931: execução de estruturas de concreto: procedimento. Rio de Janeiro.

Associação Brasileira de Normas Técnicas. (2005). NBR 9778: Argamassa e concreto endurecidos- Determinação da Absorção de Água, Índice de Vazios e Massa Específica. Rio de Janeiro.

Associação Brasileira de Normas Técnicas. (2009). NBR 7211: Agregados para concreto Especificação. Rio de Janeiro.

Associação Brasileira de Normas Técnicas. (2011). NBR 7222: Concreto e argamassa Determinação da resistência à tração por compressão diametral de corpos de prova cilíndricos. Rio de Janeiro.

Associação Brasileira de Normas Técnicas. (2012). NBR 9779: Argamassa e concreto endurecidos - Determinação da absorção de água por capilaridade. Rio de Janeiro.

Associação Brasileira de Normas Técnicas. (2013). NBR 8802: Concreto endurecido Determinação da velocidade de propagação de onda ultrassônica. Rio de Janeiro.

Associação Brasileira de Normas Técnicas. (2014). NBR 6118: Projeto de estruturas de concreto - Procedimento. Rio de Janeiro.

Associação Brasileira de Normas Técnicas. (2015). NBR 12655: Concreto de cimento Portland Preparo, controle e recebimento - Procedimento. Rio de Janeiro.

Associação Brasileira de Normas Técnicas. (2018). NBR 16697: Cimento Portland - Requisitos. Rio de Janeiro.

Associação Brasileira de Normas Técnicas. (2018). NBR 5739: Concreto - Concreto - Ensaio de compressão de corpos de prova cilíndricos. Rio de Janeiro.

Cadore, W.W. (2008). "Estudo da carbonatação da camada de cobrimento de protótipos de concreto com altos teores de adições minerais e cal hidratada”, Dissertação de Mestrado, Universidade Federal de Santa Maria. 
Castro, A. (2003). "Influência das adições minerais na durabilidade do concreto sujeito à carbonatação", Dissertação de Mestrado. Universidade Federal de Goiás.

Lima, M.G. (2015). "Ação do meio ambiente sobre as estruturas de concreto”. In: ISAIA, Geraldo Checella. (Ed) Concreto: ensino, pesquisa e realizações. São Paulo, Brasil.

Monteiro, E.C.B. (2002). "Avaliação do método de extração eletroquímica de cloretos para reabilitação de estruturas de concreto com problemas de corrosão de armaduras". Tese de Doutorado, Universidade de São Paulo.

Nascimento, R.Z. (2017). "Efeitos da sílica ativa, cinza volante, metacaulim e cinza de casca de arroz sobre a velocidade de carbonatação do concreto". Trabalho de Conclusão de Curso de Graduação, Universidade Federal do Paraná.

Papadakis, V. G., Vayegas, C. G., Fardis, M. N. (1991). Fundamental modeling and experimental investigation of concrete carbonation. ACI Materials Journal, n. 88, p. 363-373.

Ribeiro, D. V., Cunha, M. P. T. "Corrosão em estruturas de concreto armado: Teoria, controle e Métodos de análise”, Rio de Janeiro, Campus, $1^{\text {a }}$ ed., cap. 6.

Vaghetti, M. O. A. (1999). "Efeitos da cinza volante com cinza de casca de arroz ou sílica ativa sobre a carbonatação do concreto de cimento Portland". Dissertação de Mestrado, Universidade Federal de Santa Maria, p. 111.

Vieira, F. M. P. (2003). "Contribuição ao estudo da corrosão de armaduras em concretos com adição de sílica ativa". Tese de Doutorado. Universidade Federal do Rio Grande do Sul. 